\title{
“Better together!"
}

United Nations Sustainable Development Goals, SDG\#5 focuses on "Gender Equality" and 2019 year's World Maritime Day theme has been indicated as "Empowering Women in the Maritime Community" by International Maritime Organization (IMO) which is an agency of the United Nations based in London. The Day of the Seafarer 2019 was celebrated on 25th of June with the hashtag of "\#iamonboard with gender equality all around the world as IMO's campaign.

As The Chamber of Marine Engineers, Turkey we are the first organization in Turkey which lead the IMO's \#iamonboard with gender equality campaign and it brought a huge impression to the maritime industry worldwide. With the results of our cooperative work with IMO, we are so glad to announce that we have established a new international platform called "SheFarers". SheFarers Platform is non-profit and aims to create awareness on women who work at sea, to promote their careers on board and ashore with specialized educational programs, to protect rights of women on board and to facilitate working standards for all women in the industry whom involve in field work.

SheFarers Platform is established in Turkey however always focuses on brining all female seafarers together internationally and the main project area is to set up a new mentorship program for women at sea and ashore in all maritime fields by starting in Turkey. Thus, SheFarers designated a motto to encourage more women to the maritime industry which is "Better together!".

The first event of SheFarers will be held on 26th of September 2019 which is World Maritime Day and SheFarers invites all to celebrate the theme of "Empowering Women in the Maritime Community" and \#iamonboard campaign of IMO.

SheFarers is very active on social media to emphasize women's recognition in every field of the maritime industry and can be followed on the below accounts

Website: www.shefarers.org

Instagram: @she.farers

Facebook: SheFarers

Twitter: @shefarers

LinkedIn: SheFarers

Direct contact: info@shefarers.org

Capt. Ayse Asli Basak

Co-Founder, SheFarers Platform

Board Member, The Chamber of Marine Engineers, Turkey 

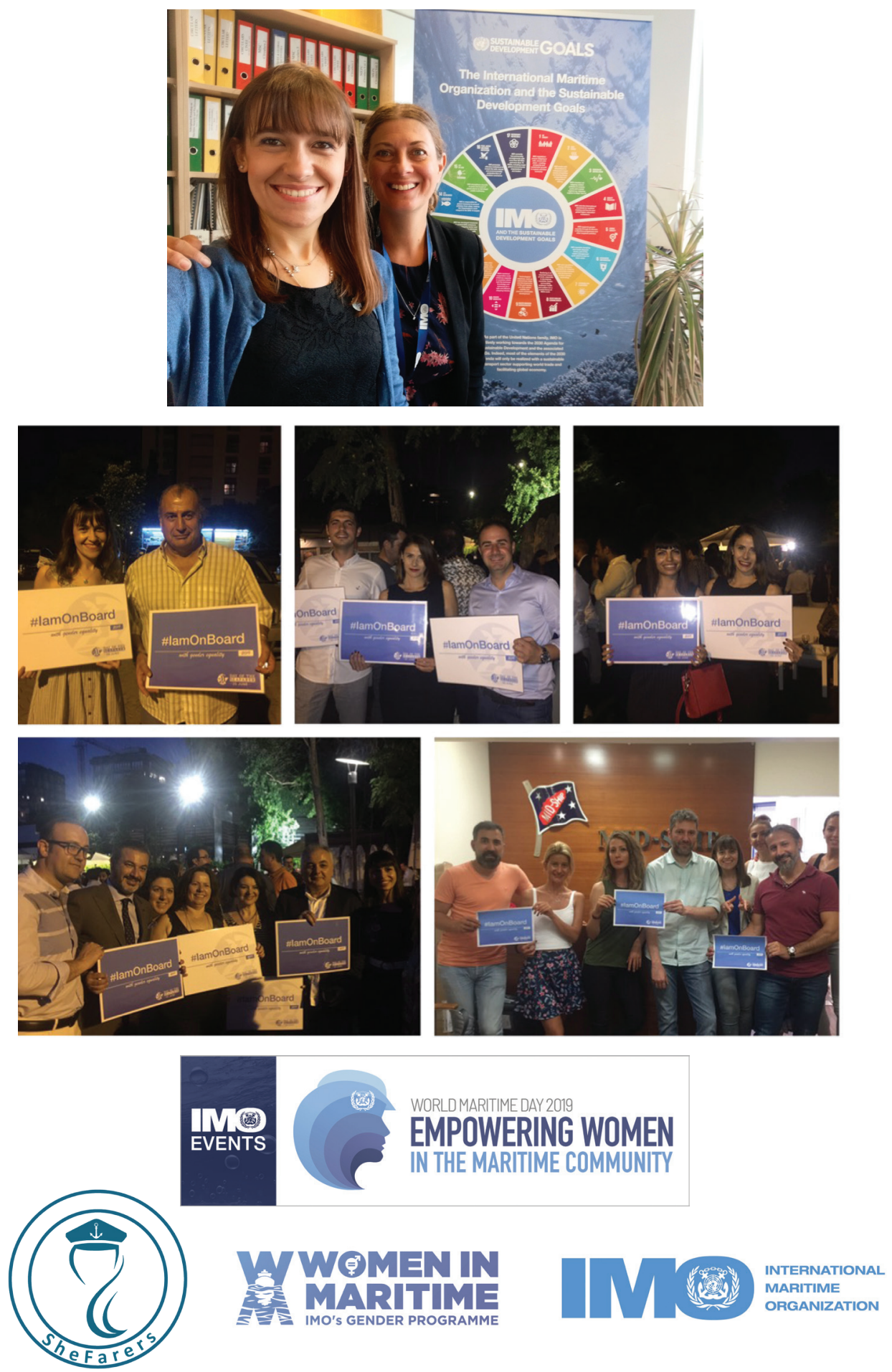